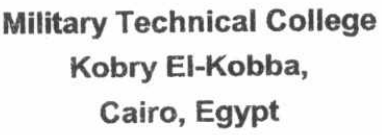



11-th International Conference

on Aerospace Sciences \&

Aviation Technology

\title{
PERFORMANCE OF WICKLESS HEAT PIPE WORKING WITH R134a
}

\author{
Ahmed" Fathy, Mohamed Afify", Karam El-Shazly"*
}

\begin{abstract}
One of the important use of heat pipes is the thermal control of satellites. The performance characteristic of a wickless copper heat pipe was investigating experimentally. For that aspect, a test rig was built up for a heat pipe with $1.4 \mathrm{~m}$ length, $18 \mathrm{~mm}$ internal diameter and $2 \mathrm{~mm}$ thickness charged with R134 a as working fluid with a temperature range from $-40^{\circ} \mathrm{C}$ to $110^{\circ} \mathrm{C}$. The evaporator section was electrically heated with heat flux varying from 200 to $600 \mathrm{~kW} / \mathrm{m}^{2}$. The condenser section was water cooled by using an overflow tank. Thermocouples were embedded on outside surface along the length of the heat pipe, and this surface was thermally insulated. The heat pipe transient responses as well as the axial distribution of wall temperature were plotted, for the three sections of the heat pipe, at different values of heat flux. The overall thermal conductance and the heat transfer coefficients at the evaporator and the condenser sections were plotted against the heat flux. These values were compared with the results published in literatures. The effect of some parameters on the heat pipe performance had been studied like the tilt angle and the adiabatic length of the pipe. The results show that the increase of the tilt angle or the adiabatic length of the pipe reduces its heat transport capacity. The correlation of Sakr and Ramadan [ 8 ] for the entrainment limit of heat pipes, had different values of $\mathrm{n}$ for R11, R12, R22 and R118 as working fluids. Applying the present results in this correlation, it had been found that $n=4.056$ for wickless heat pipe with $R 134 a$.
\end{abstract}

\section{KEY WORDS}

Satellite, Heat Pipes, thermosyphons,

\section{NOMECLATURE}

\section{Symbols}

$\begin{array}{ll}\text { A } & \text { Cross section area }\left(\mathrm{m}^{2}\right) \\ \mathbf{A}_{\boldsymbol{e}} & \text { Surface area of evaporator }\left(\mathrm{m}^{2}\right) \\ \mathbf{A}_{\mathrm{c}} & \text { Surface area of condenser }\left(\mathrm{m}^{2}\right)\end{array}$

* Graduate student, Dpt. Of Mech. Power, Military Technical College, Cairo, Egypt.

** lecturer, Dpt. Of Mech. Power, Military Technical College, Cairo, Egypt.

*** Professor. Dpt. Of Mech. Power, Shoubra Faculty of Engineering - Zagazig University, Cairo, Egypt. 


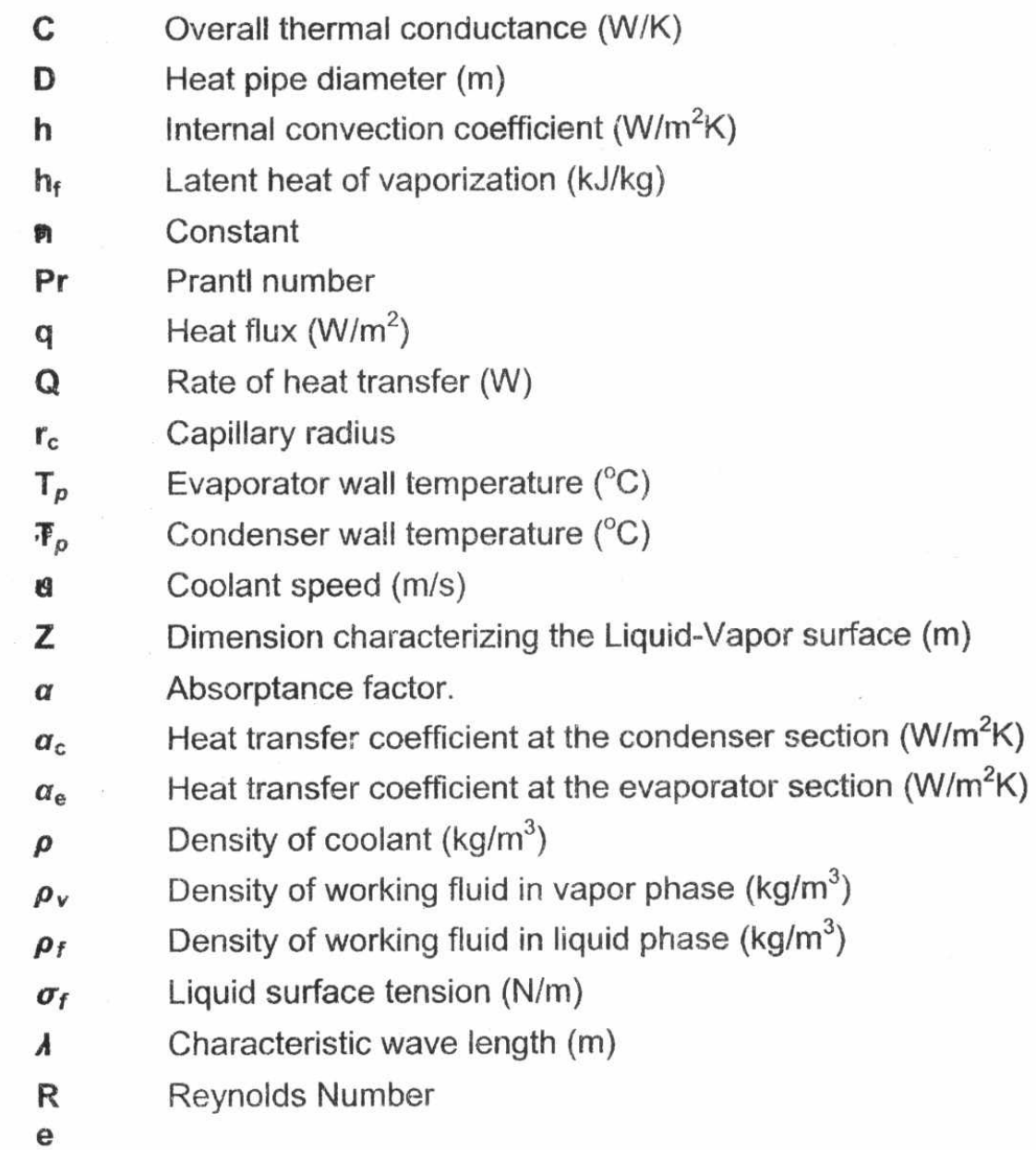

\section{introduction}

The aim of the experimental work is to investigate the effect of different parameters on the performance of heat pipes. These parameters are response of the heat pipe, heat transport capacity (boiling limit, entrainment, conductance and both the heat transfer coefficient of evaporator and condenser sections), effect of tilt angle and variation of adiabatic section length, which affect the general use of heat pipe, especially in satellites.

\section{Experimental set-up}

A wickless heat pipe which is available is shown in Figure (1) the heat pipe is maintained in the vertical position. The overhead tank is used to maintain a constant water flow rate to the condenser-cooling jacket during the experiments. The water temperature was measured at the inlet and the exit of the condenser-cooling jacket using $(\mathrm{NiCr}-\mathrm{Ni})$ thermocouples and the cooling water flow rate is measured. The evaporator section is uniformly heated using an A.C. electric heater wrapped on the 
outside of the heat pipe wall Figure (2). The electric power input to the electric tape in the experiment is measured directly using a power meter and controlled by a resistance variac. Amiant is used in insulating the heat pipe, the ends of the evaporator and the condenser sections to minimize the heat losses during the experiments. The surface temperature of the insulator is measured to determine the heat losses by natural convection in the evaporator section.

The heat pipe used in the experiments is made from standard copper tube. The tube has a length of $1400 \mathrm{~mm}$ long, an inner diameter of $18 \mathrm{~mm}$ and a wall thickness of 2 $\mathrm{mm}$. Closure of the heat pipe is made by soldering a brass cap onto each end. The heat pipe is divided into evaporator section (550 $\mathrm{mm}$ in length), condenser section ( $370 \mathrm{~mm}$ in length) and adiabatic section which separate the mentioned two sections (450 $\mathrm{mm}$ in length). The specifications of the tested heat pipe are given in table (1).

Table (1) Heat Pipe specifications

\begin{tabular}{|c|c|}
\hline Pipe Material & Copper \\
\hline Pipe Length & $1400 \mathrm{~mm}$ \\
\hline Evaporator Length & $550 \mathrm{~mm}$ \\
\hline Adiabatic Length & $450 \mathrm{~mm}$ \\
\hline Condenser Length & $370 \mathrm{~mm}$ \\
\hline Pipe Outside Diameter & $22 \mathrm{~mm}$ \\
\hline Pipe Inside Diameter & $18 \mathrm{~mm}$ \\
\hline Working Fluid & $\mathrm{R} 134 \mathrm{a}$ \\
\hline Temperature range & $-40-110^{\circ} \mathrm{C}$ \\
\hline
\end{tabular}

The evaporator section is located at the lower end of the pipe and thermal power is supplied by means of a Nickel-Chrome electrical resistance $(3.334 \mathrm{ohm} / \mathrm{m})$. The evaporator wall temperature is measured by means of eight calibrated $(\mathrm{NiCr}-\mathrm{Ni})$ thermocouples. The thermocouples are embedded on the outside wall of the evaporator section and spaced on the evaporator circumference along the length. Similarly, the adiabatic section is insulated by Aminate and its surface temperature is measured by eight equally spaced calibrated thermocouples of the same type. The output of the thermocouples is received by a calibrated volt meter. The details of the tested heat pipe are shown in figure (2), while figure (3) shows the locations of the thermocouples along the heat pipe. 


\section{Overhead water tank}

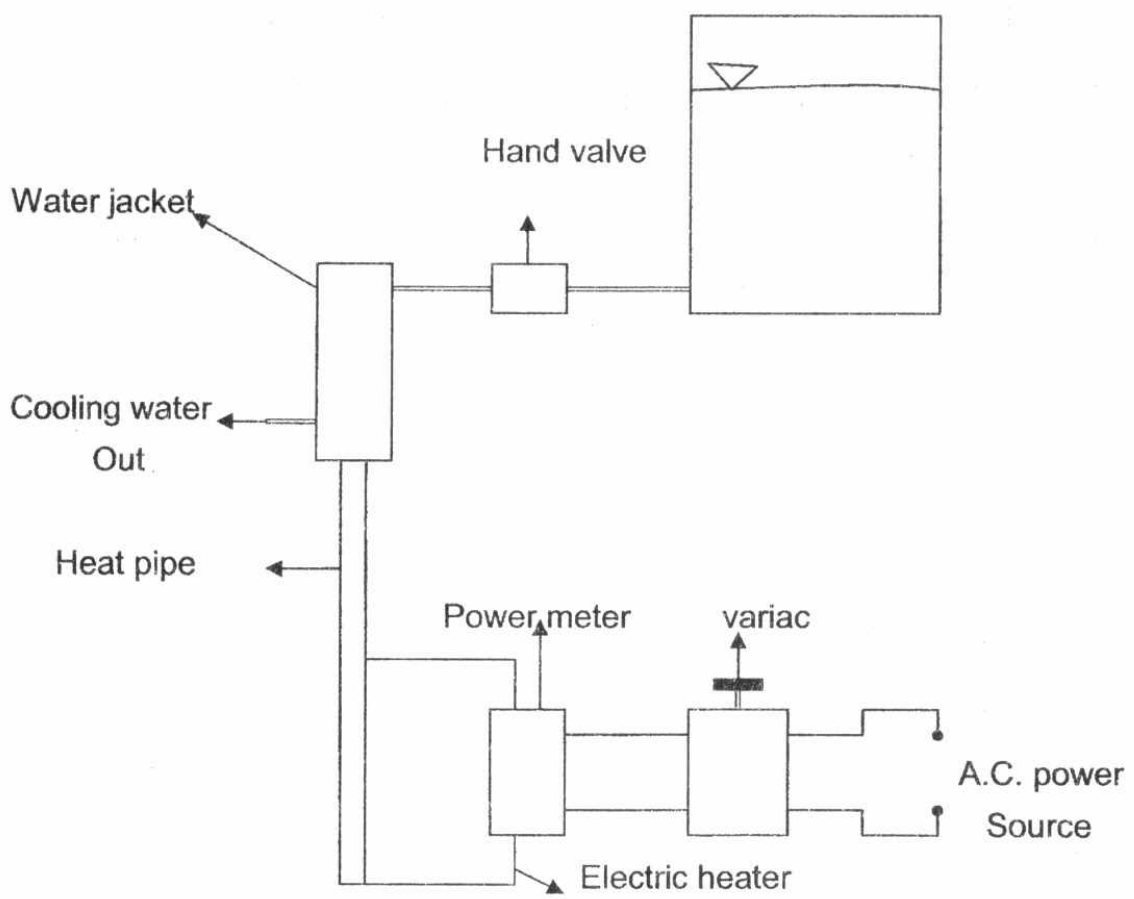

Figure (1) schematic diagram of the experimental setup

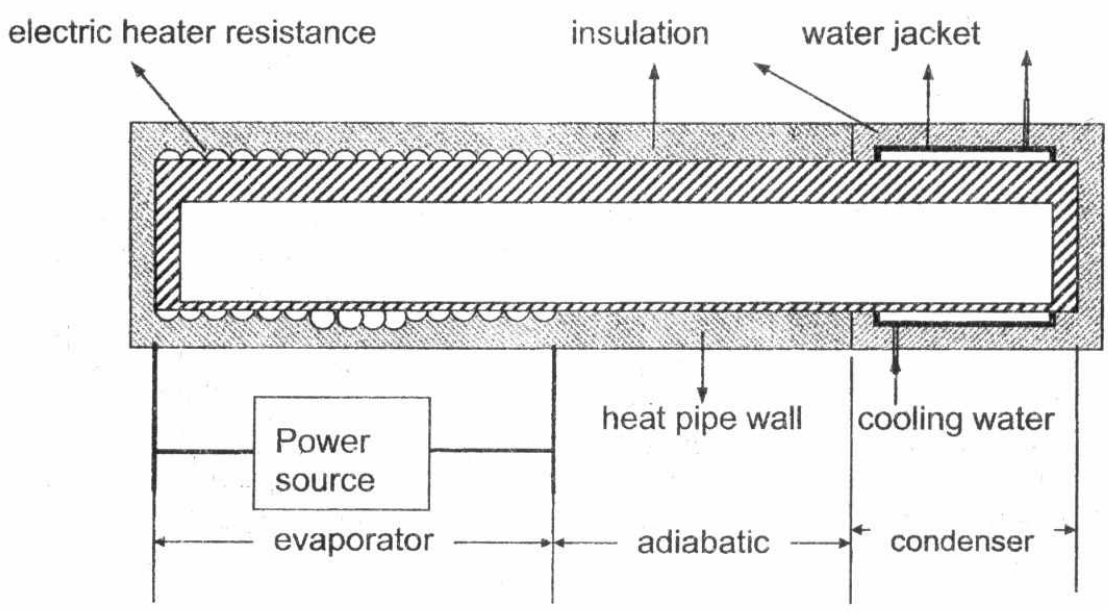

Figure (2) longitudinal cross-section of heat pipe 


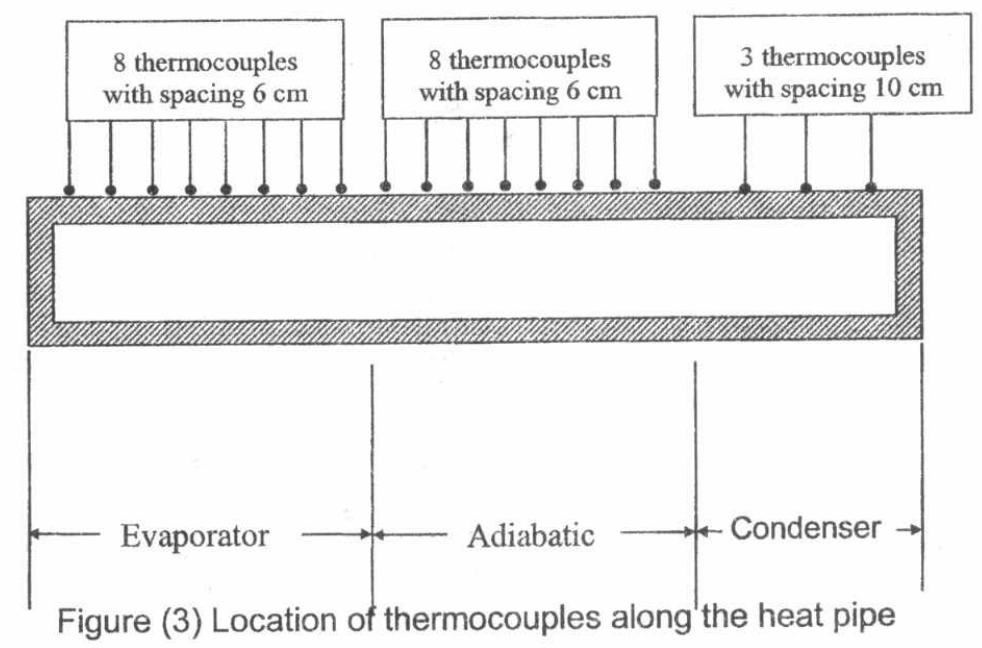

Cooling is accomplished by circulating water at normal ambient temperature through a cooling jacket mounted around the condenser section of the heat pipe. This jacket is made from an insulated steel pipe of $42 \mathrm{~mm}$ outer diameter and $4 \mathrm{~mm}$ wall thickness. Three calibrated ( $\mathrm{NiCr}-\mathrm{Ni}$ ) thermocouples are used to measure the surface temperature of condenser. The inlet and outlet water temperatures are measure by ( $\mathrm{NiCr}-\mathrm{Ni})$ thermocouple.

\section{Experimental procedure}

Supplying maximum power to the evaporator heater resistance with an inactive condenser starts the series of experiments. As soon as the maximum system pressure has reached a desired value, coolant is circulated through the condenser jacket.

A constant working pressure is achieved by equalizing the rate of heat added to the evaporator to that rejected from the condenser.

When a steady state is reached (within $30-50 \mathrm{~min}$ ), temperature and power readings are recorded. The heat flux is then decreased in steps to change the operating conditions. A sufficient time is allowed to stabilize the state of boiling at measurement steps.

\section{Experimental Results}

The purpose of the present study is to investigate experimentally the performance characteristics of a wickless heat pipe (two-phase closed thermosyphons); Variation of heat flux at the evaporator section, heat pipe tilt angle and the adiabatic section length of the heat pipe are the major parameters investigated. The effect of the aforementioned parameters on the heat pipe transient response, output heat flux, surface temperature along the heat pipe, heat transfer coefficient at both the evaporator and condenser sections and the overall thermal conductance are shown in the following sections. 


\section{Heat pipe transient response}

Before conducting the experiments, the water flow rate in the cooling jacket is adapted at the desired value. The transient is initiated by increasing the electric power to the heating heater at the evaporator section in steps, from zero to the required value, using the variac in the electric circuit (Fig. 1). The heat-up phase of the experiment continued until steady state is reached. Then, the electric power to the evaporator section is reduced in a step function to zero, but the cooling water flow rate is kept unchanged. At the end of the cool-down phase of the experiment, the heat pipe and the insulation are cooled down to almost room temperature, and then another transient is initialed.

Figure (4) presents the results of transient response of the heat pipe use R134a to step function increase in electric power input. During the transient the electric power the cooling water flow rate, and inlet water temperature are kept constant .The heat pipe reached steady state approximately after 40 to 50 min. Higher values of wall temperature are observed at the evaporator section.

Figure (5) presents snapshots of the measured axial distributions of wall temperatures at different intervals during the transient. The wall temperatures in the evaporator, adiabatic and condenser sections are almost uniform .The maximum variation in the measured wall temperature is less than $9^{\circ} \mathrm{C}$.

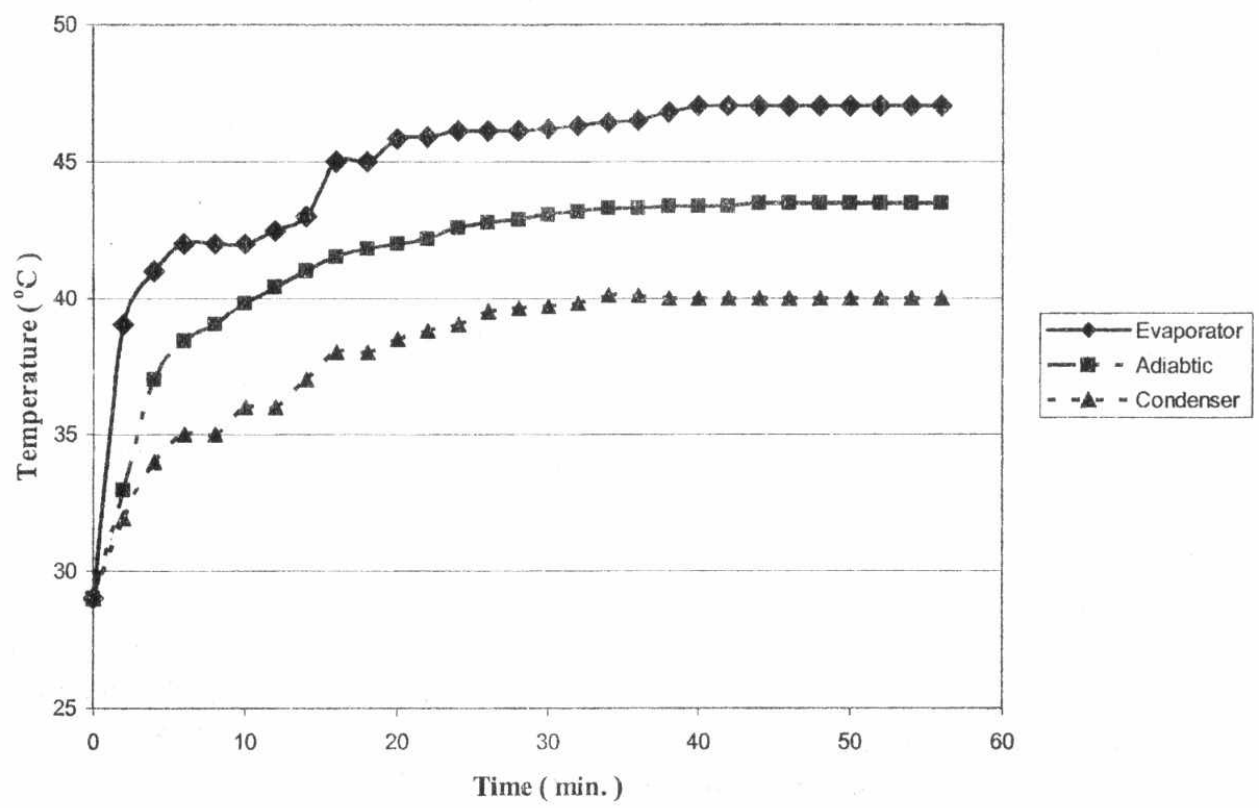

Figure (4) Transient response of Heat pipe zones 




Figure (5) Transient axial distribution of wall temperatures

Abou-Ziyan et al [7] observed during their experiments that the mean temperature at adiabatic section is very close to the saturation temperature of the working fluid and El-Genk and Huang [10] considered it at the end of adiabatic section. Those results are used for determination of heat transfer coefficients at the evaporator and condenser sections.

\section{Heat transport capacity}

The experimental procedure is started by applying the required power to the heater. Then adjusting the water flow rate in the condenser to achieve reasonable temperature difference across it. The input power to the heater is raised gradually to start a new experiment. All the experimental parameters are measured after the steady sate is attained. The heat transport rate is determined by measuring the water inlet and outlet temperatures and water flow rate. The conduction heat loss from the heater surface is evaluated by measuring the temperatures across the insulation layer. The actual heat input to the evaporator section is the difference between the electrical input power and the estimated heat loss.

Figure (6) shows the output heat flux as function of input heat flux for R134a the output heat flux increases with input heat flux up to $q_{\text {in }}=295 \mathrm{~kW} / \mathrm{m}^{2}$ (based on cross section area). After that the output heat flux decreases as the input heat flux is increased because the thermosyphon is operated in abnormal conditions indicated by the increase in adiabatic and evaporator temperatures as seen in figure (7). 
Figure (8) shows the surface temperatures along the heat pipe. The wall temperature in evaporator, adiabatic and condenser sections is almost uniform. The difference in temperature is within $(7-20){ }^{\circ} \mathrm{C}$. This figure shows that at low input heat fluxes the temperature differences is small and by increasing the input heat flux the temperature difference increase due to the dryout conditions of the evaporator.

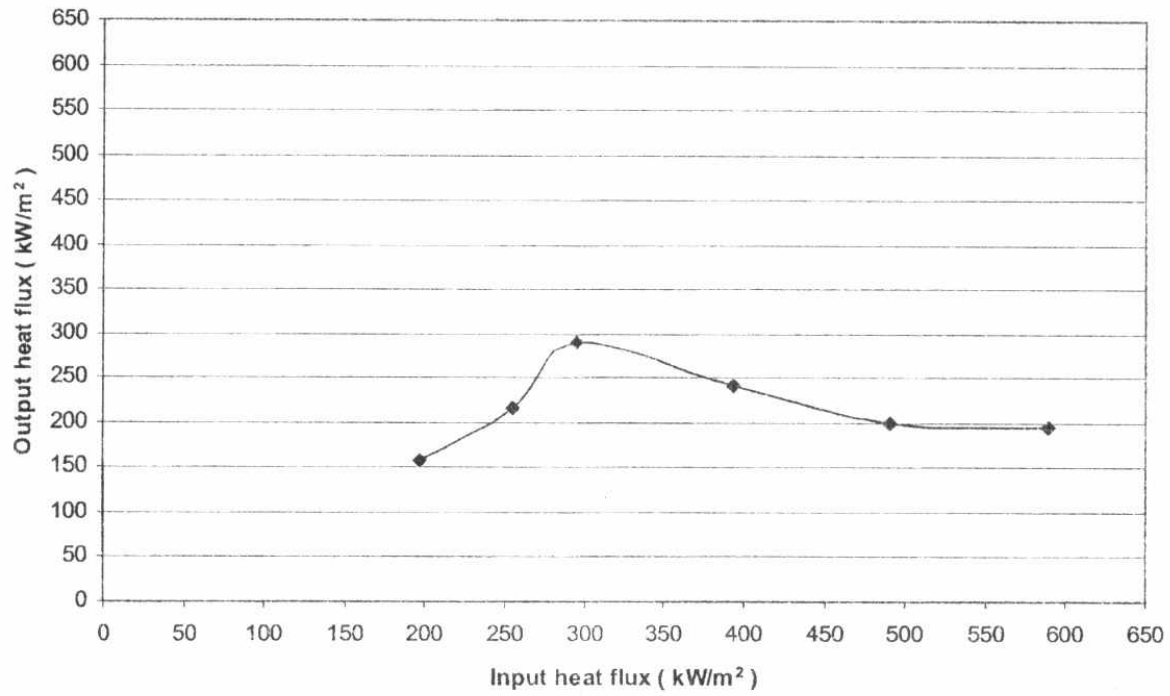

Figure (6) Heat Transport Capacity



Figure (7) Evaporator and Adiabatic temperatures with heat flux 


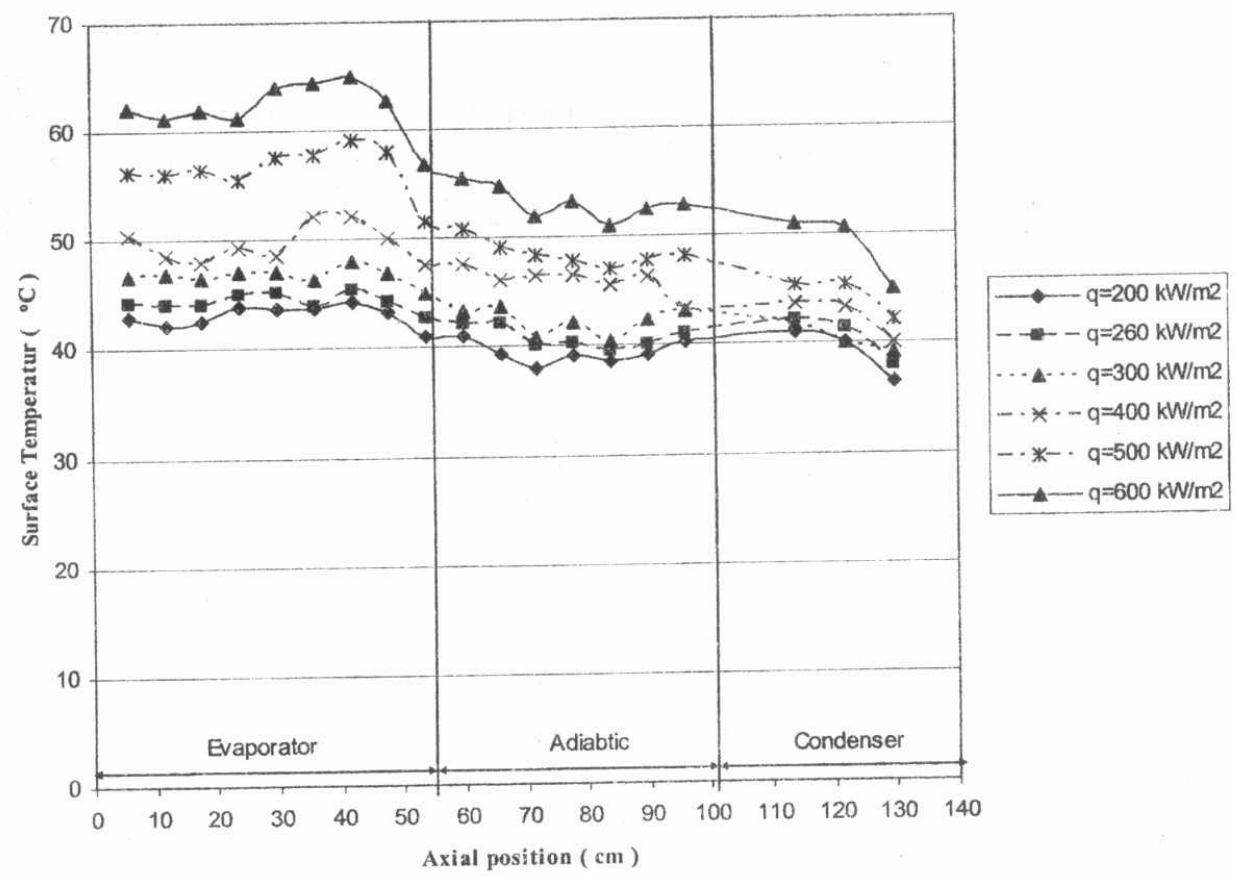

Figure (8) Surface temperature distribution along the heat pipe

The heat transfer coefficient at the evaporator section is calculated using the experimental data from the following relation:

$$
\alpha_{e}=\frac{Q}{A_{e}\left(T_{p, e}-T_{v}\right)}
$$

The heat transfer coefficient at the evaporator section is calculated from the relation:

$$
\alpha_{c}=\frac{Q}{A_{c}\left(T_{v}-T_{p, c}\right)}
$$

Finally, the overall thermal conductance is calculated from the relation:

$$
C=\frac{Q}{\left(T_{p, e}-T_{p, c}\right)}
$$


The experimental results are represented on linear plots of the heat transfer coefficient against the heat flux. Figures $(9,10)$ show this relation for the evaporator and condenser sections respectively. As shown in these figures, at constant working pressure, the evaporator and condenser heat transfer coefficients increase rapidly with the increase of the heat flux (based on surface area) at the evaporator and condenser section up to $\left(q=1973 \mathrm{~W} / \mathrm{m}^{2}\right)$. Then they decrease due to the dry-out conditions.

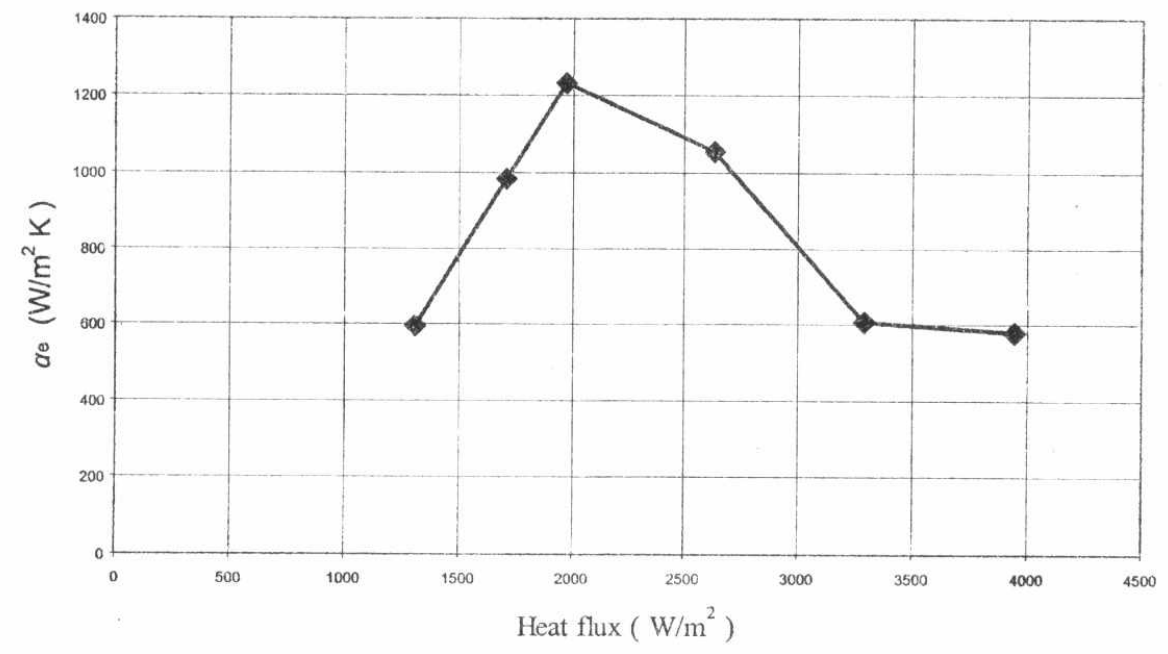

Figure (9) Effect of heat flux on the evaporator heat transfer coefficient

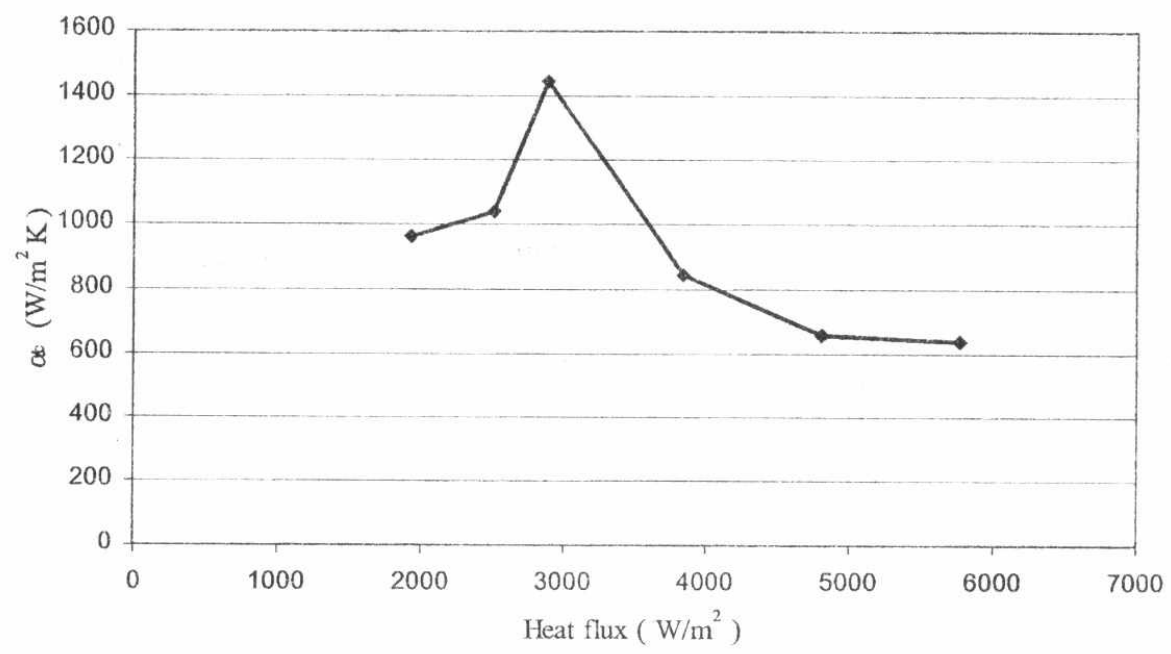

Figure (10) Effect of heat flux on the condenser heat transfer coefficient 
Figure (11) shows the variation of the input power with the thermal conductance, as shown in figure the thermal conductance increases up to $(Q=75 \mathrm{~W})$ then it decreases due to dry-out conditions

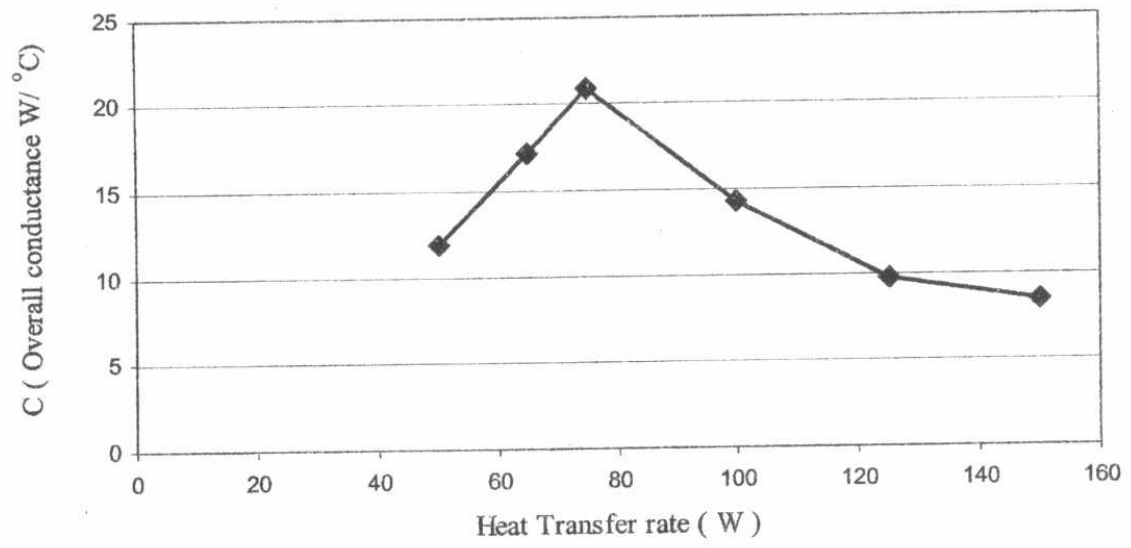

Figure (11) Effect of input power on the thermal conductance

\section{Effect of Tilt angle of Heat Pipe}

Figure (12) shows the effect of tilt angle on the heat transport rate. The output power for different tilt angles (angles 0,30,60 and 90) at constant heat flux $\left(q=1973 \mathrm{~W} / \mathrm{m}^{2}\right)$. The maximum heat transport rate is achieved at vertical position and it decrease before and after the peak value.



Figure (12) Effect of tilt angle on the heat transport rate 


\section{Effect of adiabatic section length}

In this experiment replacing portion of adiabatic section by condenser section, the experiment is repeated for the adiabatic section lengths of $45 \mathrm{~cm}, 25 \mathrm{~cm}$ and $5 \mathrm{~cm}$. Noting that the heat transport rate increases as the adiabatic section decreases or in other hand as the condenser section increases that for capability of heat pipe to transfer large amount of heat is enhanced as shown in figures (13) and (14).



Figure (13) Effect of adiabatic section length on heat transport rate

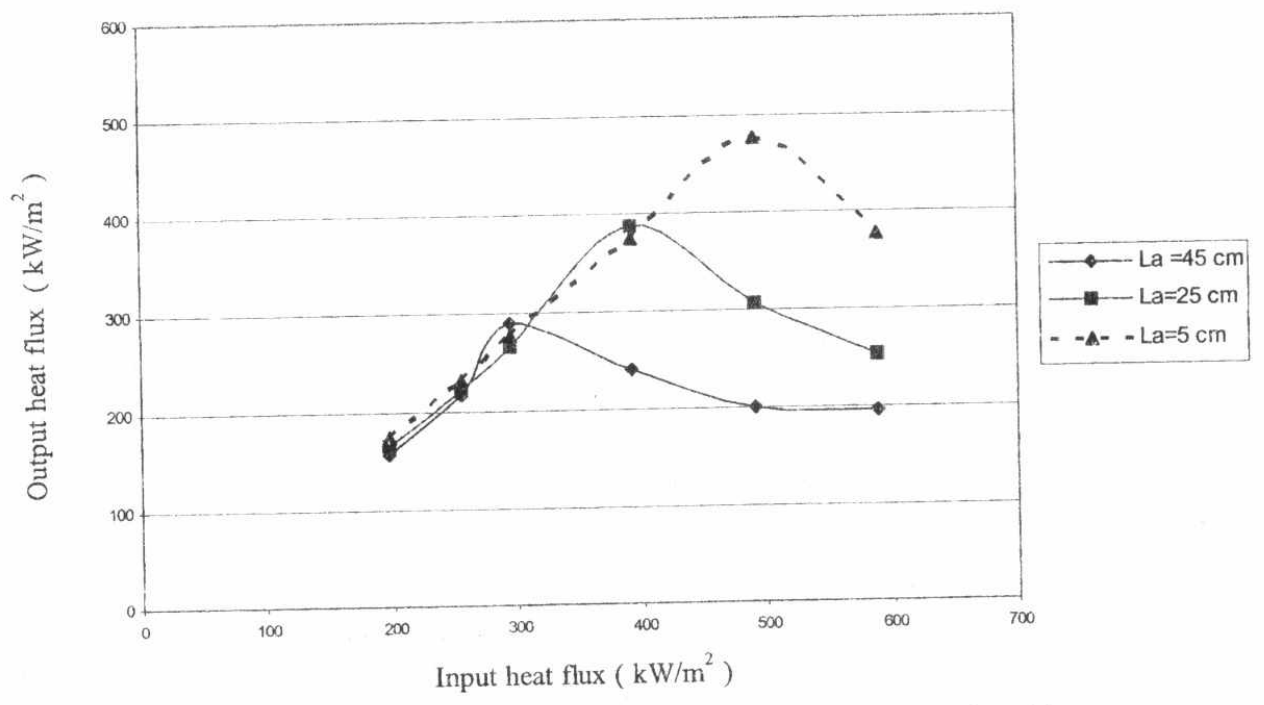

Figure (14) Effect of adiabatic section length on output heat flux 


\section{Comparison of experimental results with literatures}

\section{Effect of adiabatic length}

Silverstein [2] studied the effect of replacing a portion of the condenser section length by an adiabatic length. He reported higher heat transport rate as the adiabatic section length decreases while the condenser section length increases. Abou-Ziyan et al [7] studied the effect of increasing adiabatic section length while the lengths of condenser and evaporator sections remained constant. He reported that the capability of thermosyphon to transfer large amount of heat is enhanced as the adiabatic section length increases.

\section{Entrainment and flooding limit}

The two-phase closed themosyphon operates under some limits, namely sonic, flooding or entrainment, dryout and boiling. For large liquid fill ratios $(>0.2)$, critical heat flux is based on flooding and boiling limits whereas for fill ratio less than 0.2 , the critical limits are mainly dryout and boiling, Faghri [1]. In the present work the liquid fill ratio $(>0.2)$, thereby the boiling and entrainment limits are considered. The entrainment limit is evaluated based on correlation reported by Faghri [1].

Figure (15) compares the present results of the heat pipe heat transport capacity with the results of Abou-Ziyan et al [7]. The two curves almost have the same behavior but different in the peak point (Abou-Ziyan et al [7] $\mathrm{q}_{\mathrm{in}}=220 \mathrm{~kW} / \mathrm{m}^{2}$ ) due to the difference in operation conditions (Abou-Ziyan et al [7] used copper pipe of 23 and $25 \mathrm{~mm}$ inner and outer diameter and $900 \mathrm{~mm}$ total length), with refrigerant R134a as the working fluid.

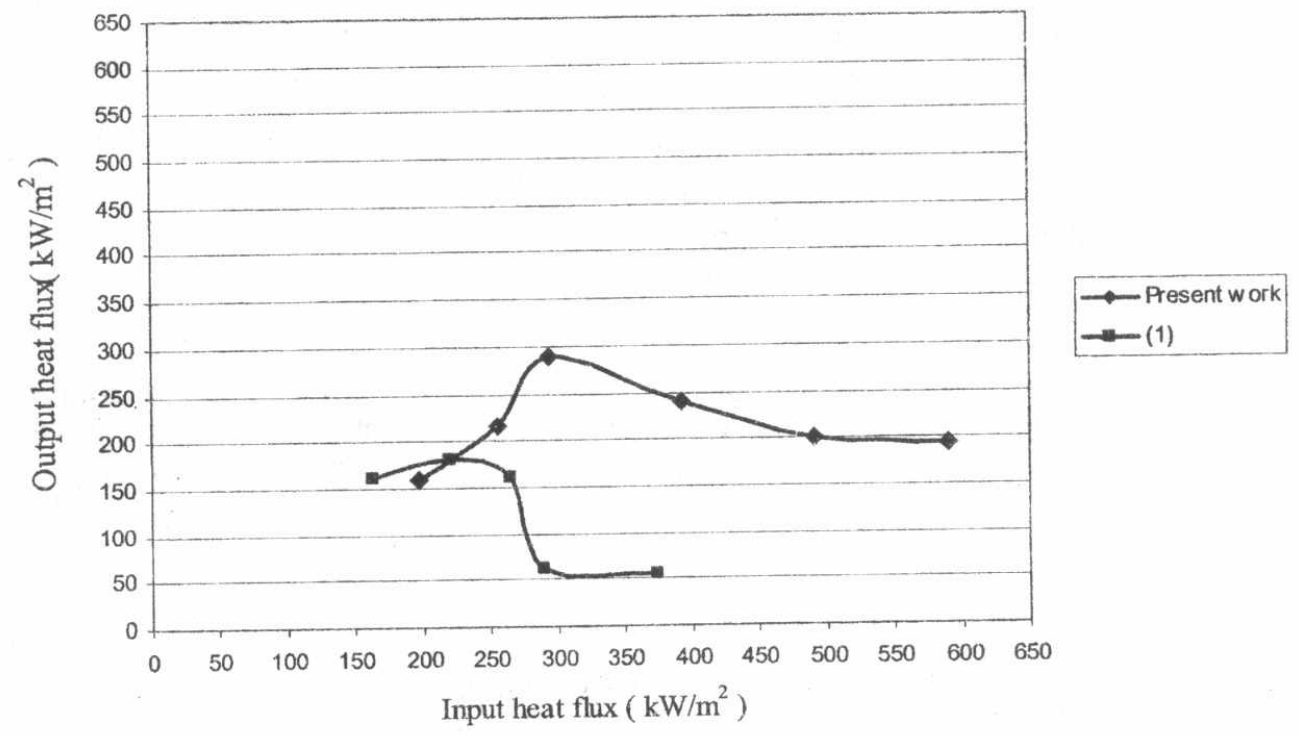

Figure (15) Comparison of heat transport capacity between present results and previously published results [7] at different heat fluxes 
As stated by Nguyen-Chi and Groll [11], the entrainment limit occurs for large fill charges, and high axial heat flows, but small radial evaporator heat fluxes. The high axial heat flow causes a high relative velocity between the counter current vapor and liquid flows. Consequently the shear forces at the vapor liquid interface are increased and thereby, large surface waves are induced there. Thus instability of the liquid flow is created, which leads to an entrainment of liquid. The entrained liquid is transported to the condenser by the vapor flow and collected there. The high shear forces can also stop completely returning the condensate back to the evaporator and hence, the condensate flow breaks up at the flooding point. In any case, the intense entrainment or flooding causes an insufficient liquid supply to the evaporator. This leads to a local dry-out and ultimately to a complete dry-out of the evaporator. For entrainment limit Weber number defined by equation (4) equals one. The increasing of Weber number increases the evaporator dry-out and the condenser flooding.

At the evaporator inner surface, heat is dissipated to the working fluid. Then it begins to boil and the nucleate boiling is initiated. As the temperature increases further, bubbles formed so rapidly that blankets the heating surface and prevents the inflow of fresh liquid from taking their place and the surface temperature increases rapidly, that we call dry-out.

$$
W_{e}=\frac{\rho u^{2} L}{2 \pi \sigma_{f}}
$$

Accordingly, both the theoretical and experimental investigations of the previous investigators are considered. Tien and Chung [5] developed an elementary mathematical model to investigate the entrainment limit for gravity assisted heat pipes. Prenger and Kemme [3] carried out experiments using gravity assisted heat pipes with simple wick structures. These models were used to establish the performance limits due to entrainment of the liquid by counter flowing vapor. Prenger [4] developed physical model based on a stability analysis at the liquid-vapor interface. The model was used to describe the experimental behavior of heat pipes with either smooth or textured wall. Dunn and Reay [12] introduced a correlation for the thermosyphon entrainment limit which states:

$$
Q=A h_{f 8} \sqrt{\frac{2 \pi \rho_{v} \sigma_{f}}{Z}}
$$

where $\mathbf{Z}$ is a dimensionless parameter characterizing the vapor liquid interface. Rice and Fulford [6] modified this model twice to be applied in heat pipe with mesh screen. Prenger and Kemme [3] re-correlate the Dunn and Reay [12] model to become:

$$
Q=A h_{f g} \sqrt{\frac{\rho_{v} \sigma_{f}}{\lambda}}
$$

where $\lambda$ is the characteristic wave length calculated from:

$$
\lambda=\sqrt{\frac{\sigma_{f}}{\left(\rho_{f}-\rho_{v}\right) g}}
$$


While Ivanovskii et al. [9] re-correlate the Dunn and Reay [12] model to become:

$$
Q=A h_{f g} \sqrt{\frac{2 \pi \rho_{\nu} \sigma_{f}}{D}}
$$

where $D$ is the pipe diameter. Also, Ivanovskii et al. [9] model is re-correlated by Abo El-Nasr [28] to become:

$$
Q=A h_{f g} \sqrt{\frac{\pi \rho_{\nu} \sigma_{f}}{D}}
$$

Sakr and Ramadan [8] re-correlated equation (6) to fit the obtained experimental data as follows:

$$
Q=A h_{f g} \sqrt{\frac{\rho_{v} \sigma_{f}}{\lambda . n}}
$$

where $n$ is constant relating to both the thermo-physical properties of the working fluid and the roughness of the heat pipe inner surface, and used for the working fluids ( R-11,R-12,R-22 and R-118).

By using equation (9) to calculate $n$. It is found that $n=4.056$ for wickless heat pipe using R134a and comparing it with the results of Sakr and Ramadan [8] for other refrigerants see table 2 .

Table (2) Value of constant $\mathrm{n}$ for different working fluids

\begin{tabular}{|c|c|}
\hline Heat pipe working fluid & Constant $\mathbf{n}$ \\
\hline R11 & 9.050 \\
\hline R12 & 1.323 \\
\hline R22 & 16.663 \\
\hline R118 & 81 \\
\hline R134a & $\mathbf{4 . 0 5 6}$ \\
\hline
\end{tabular}

\section{Heat transfer coefficients and thermal conductance}

Figures $(16,17$ and 18$)$ show the comparison of present work with the results of Sakr and Ramadan [8]. It is observed that they have the same behavior only in the first part of the curve but the difference is due to the different specifications of heat pipe used as seen from table 3 . 
Table (3) Sakr and Ramadan [8] Heat pipe specifications

\begin{tabular}{|c|c|}
\hline Pipe Material & Copper \\
\hline Pipe Length & $700 \mathrm{~mm}$ \\
\hline Evaporator Length & $275 \mathrm{~mm}$ \\
\hline Adiabatic Length & $145 \mathrm{~mm}$ \\
\hline Condenser Length & $280 \mathrm{~mm}$ \\
\hline Pipe Outside Diameter & $20 \mathrm{~mm}$ \\
\hline Pipe Inside Diameter & $18 \mathrm{~mm}$ \\
\hline Working Fluid & $\mathrm{R} 22$ \\
\hline
\end{tabular}

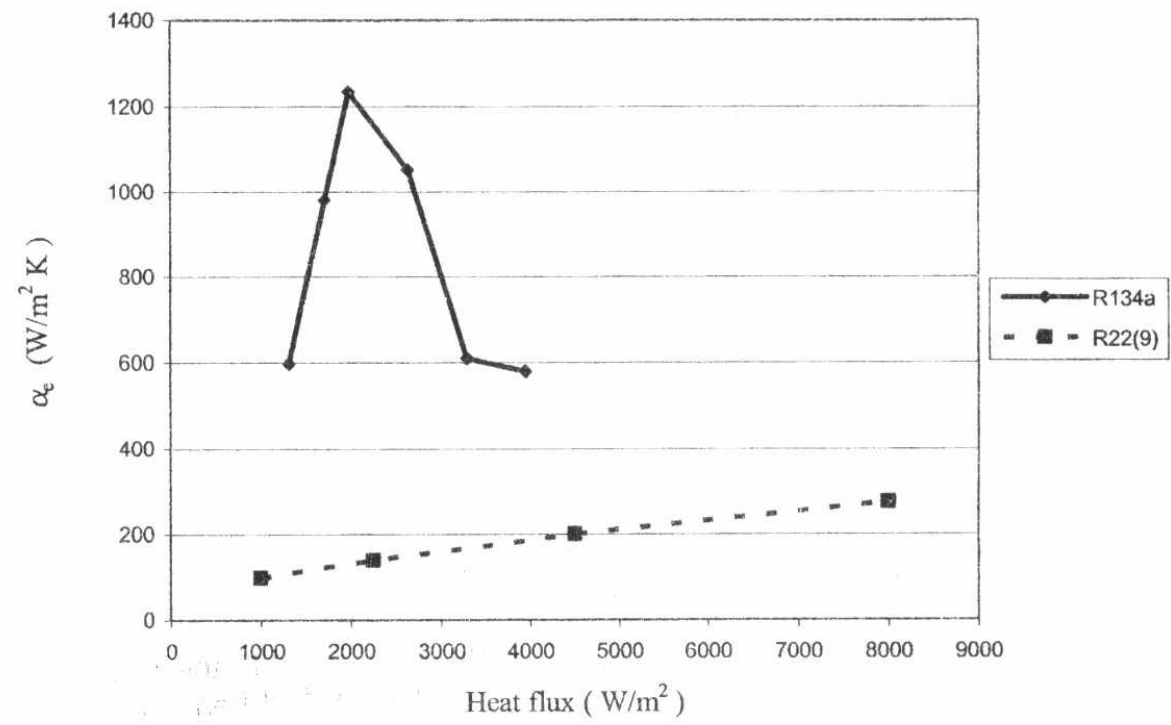

Figure (16) Comparison of evaporator heat transfer coefficient between the present results and previously published results [8] 


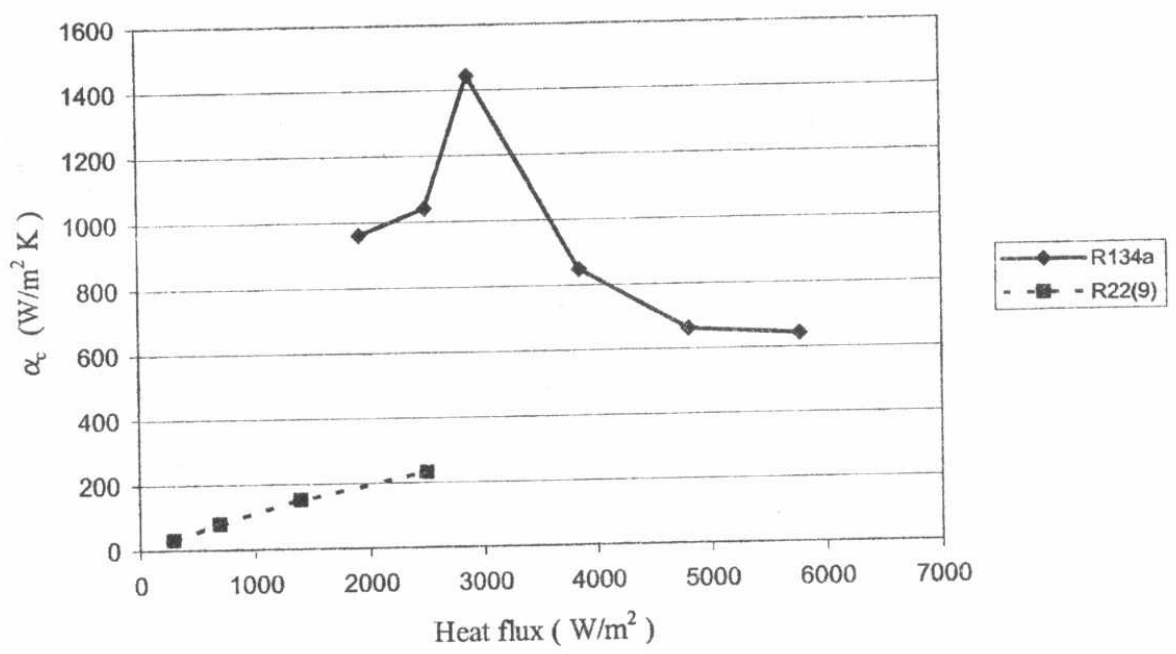

Figure (17) Comparison of condenser heat transfer coefficient between the present results and previously published results [8]

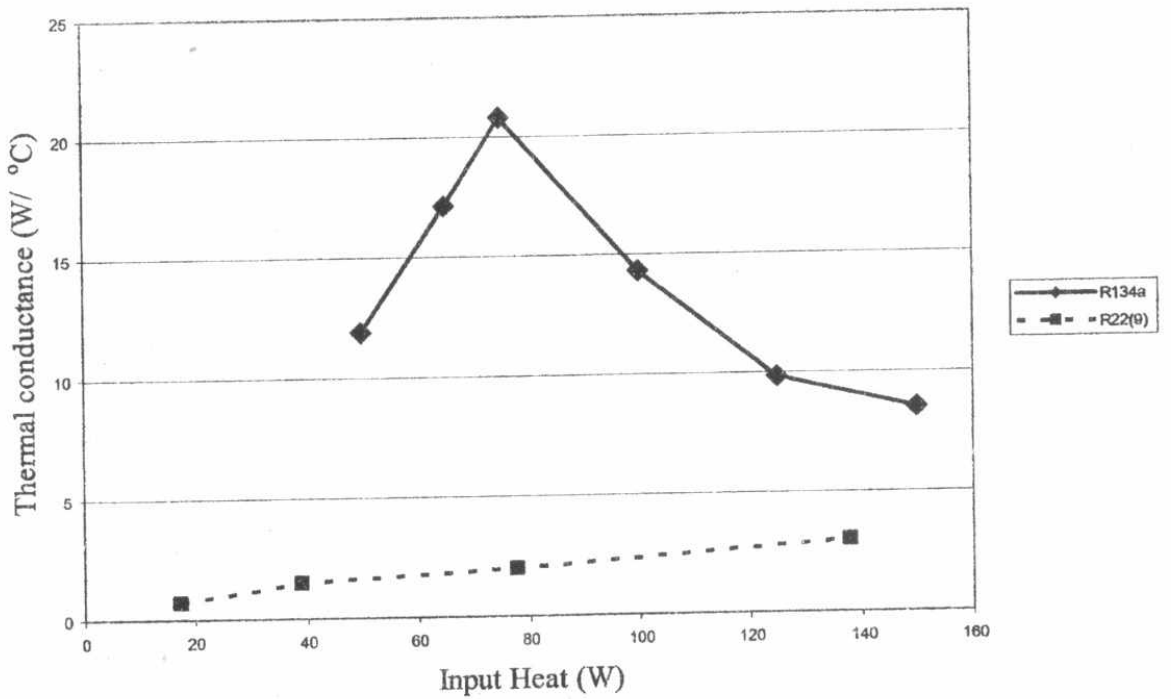

Figure (18) Comparison of thermal conductance between the present results and previously published results [8] 


\section{CONCLUSIONS}

Experiments are performed with a wickless heat pipe working with R134a having uniform heated evaporator section and water cooled condenser section. The results showed that:

1- The transient response experiments showed that the temperature different along the heat pipe may not exceed 9 ${ }^{\circ} \mathrm{C}$.

2- The heat transport capability experiments showed that the output power and the evaporator and condenser heat transfer coefficient depend on the entrainment limit and dry-out conditions, which may depend on the properties of working fluid. By applying equation (10) achieved by Sakr and Ramadan [8] with the present experimental results, the constant $\mathbf{n}$ for R134a is determined.

3- The tilt angle experiments showed that the wickless heat pipe could not work without gravity assistance. So, it may recommend that the heat pipes used in satellite to be wicked heat pipes.

4- The adiabatic length experiments showed that the replacement of a portion of the adiabatic length with the condenser length (increasing the condenser section length) could enhance the heat transport of wickless heat pipe.

\section{REFERENCES}

[1] A. Faghri, Heat Pipe Science and Technology, Taylor and Francis, Washington, DC, USA, 1995.

[2] C. C. Silverstein, Design and Technology of Heat Pipes for Cooling Heat Exchanger, Taylor and Francis, Washington, DC, USA, 1992.

[3] C. F. Prenger and J. E. Kemme, Performance Limits of Gravity Assist Heat Pipes with Simple Wick Structures, second international heat pipe conference, Bologna, Italy, 1976.

[4] C. F Prenger., Performance Limits of Gravity Assisted Heat Pipes, $5^{\text {th }}$ International Heat Pipe Conference, Tokyo 1984.

[5] C. L. Tien and K. S. Chung, Entrainment Limits in Heat Pipes, 2nd International Heat Pipe Conference, Bologna, Italy, March/April 1976

[6] G. Rice and D. Fulford, Influence of a Fin Mesh Screen on Entrainment in Heat Pipes, 6th international heat Pipe conference, France 1987.

[7] H.Z. Abou-Ziyan, A. Helali ,M.Fatouh and M. M. Abo El-Nasr , Performance of Stationary and Vibrated Thermosyphon Working with Water_and R134a, Dept. of Mech. power Eng. Faculty of Eng. (Mattaria). 
[8] M. H. Sakr and R. M. Abo El-Aziz, An Investigation into the Effect of the Working Fluid Properties on the Performance of Gravity Assisted Heat Pipe, Al-Azhar Engineering Fourth International Conference, pp. 147-159, Cairo, Egypt 1995.

[9] M. N. Ivanovskii, V. P. Sorokin and I.V Yagodkin, The Physical Principles of Heat Pipes, Oxford, University Press, New York (1982).

[10] M. S. El-Genk and Lianmin Huang, An Experimental Investigation of the Transient Response of a Water Heat Pipe. Int. J. Heat Mass Transfer, Vol.36 No. 15, 1993.

[11] Nugen-Chi and H. Groll, entrainment or flooding limit in a closed two-phase thermosyphon, advance in heat pipe technology, $4^{\text {th }}$ international heat pipe conference, London, Pergaman press, Oxford , pp. 147-162, September 1982 .

[12] P. D. Dunn and D. A. Reay, Heat Pipes, Third Addition Pergman Press, Oxford 1982. 